\title{
Synthetic Unit Hydrograph Methods: A Critical Review
}

\author{
P.K. Bhunya*,1, S.N. Panda ${ }^{2}$ and M.K. Goel ${ }^{1}$ \\ ${ }^{I}$ National Institute of Hydrology, Roorkee-247 667, UA, India \\ ${ }^{2}$ Indian Institute of Technology, Kharagpur-731302 WB, India
}

\begin{abstract}
The present study critically reviews the synthetic unit hydrograph (SUH) methods available in hydrologic literature. The study reveals that the traditional methods of SUH derivation, e.g., Snyder, SCS, traditional methods like Snyder and TS method that does not yield satisfactory results, and their application to the practical engineering problems is tedious and combursome. On the other hand, probability distribution functions (pdfs) based SUH methods are easy to apply, and easily meet the UH criterion, i.e. the area under the curve is unity, and rely on a stronger mathematical base and sounder hydrologic perception. The recent pdfs used for deriving UHs in ungauged catchments, address the SUH shapes with more flexibility than the earlier pdfs proposed by [1] for SUH derivation.
\end{abstract}

Keywords: Synthetic unit hydrograph, Probability distribution function, Peak flow rate, Time to peak, Soil Conservation Service Horton order ratios, Geomorphologic parameters.

\section{INTRODUCTION}

The unit hydrograph concept proposed by [2] for estimating the storm runoff hydrograph at the gauging site in a catchment corresponding to a rainfall hyetograph, is still a widely accepted and admired tool in hydrologic analysis and synthesis. This was one of the first tools available to hydrologic community to determine the complete shape of the hydrographs rather than the peak discharges only [3]. Since the UH concept needed the observed rainfall-runoff data at the gauging site for hydrograph generation, the paucity of these data sparkled the idea of synthetic unit hydrograph (SUH) concept.

The term "synthetic" in synthetic unit hydrograph denotes the unit hydrograph (UH) derived from watershed characteristics rather than rainfall-runoff data $[4,5]$. The beginning of the synthetic unit hydrograph concept can be traced back to the distribution graph proposed by [6] to synthesize the UH from watershed characteristics, rather than the rainfall-runoff data [7]. The example of some of the traditional methods of SUHs can be referred in [8-13]. Their simplicity and ease in development can characterize these synthetic or artificial unit hydrographs, and require less data and yield a smooth and single valued shape corresponding to one unit runoff volume, which is essential for unit hydrograph derivation. These methods utilize a set of empirical equations relating the physical characteristics of watershed to the few salient points of the hydrograph such as peak flow rate $\left(\mathrm{Q}_{\mathrm{p}}\right)$, time to peak $\left(\mathrm{t}_{\mathrm{p}}\right)$, time base $\left(\mathrm{t}_{\mathrm{B}}\right)$, and $\mathrm{UH}$ width at $0.5 \mathrm{Q}_{\mathrm{p}}$ and $0.75 \mathrm{Q}_{\mathrm{p}}$ i.e. $\mathrm{W}_{0.5}$ and $\mathrm{W}_{0.75}$, respectively.

However, in the SUH development a great degree of subjectivity is involved in fitting the remaining points on the SUH. In addition, simultaneous adjustments are required for

\footnotetext{
*Address correspondence to this author at the National Institute of Hydrology, Roorkee-247 667, UA, India; Tel: +91-01332-249221; Fax: +9101332-272123; E-mail: Pkb@nih.ernet.in
}

the area under the SUH to be the unity corresponding to unit rainfall-excess. The empirical equations involve certain constants, which vary over wide range, (e.g.,) the Snyder's proposed non-dimensional constants $\mathrm{C}_{\mathrm{t}}$ and $\mathrm{C}_{\mathrm{p}}$ which vary in the range of 1.01-4.33, 0.23-0.67 [14], 0.4-2.26, 0.31-1.22 [15], respectively. Earlier, the direct surface runoff hydrographs were obtained using linear base flow separation, and adjustments of the UH properties by [16].

Due to similarity in the shape of the statistical distributions and a conventional unit hydrograph, several attempts have been made in the past to use their probability distribution function (pdfs) for derivation of the SUH [17-22]. Based on the concept of $\mathrm{n}$ linear reservoirs in series, Nash and Dooge $[23,24]$ independently developed the general equation of the IUH in the form of two-parameter gamma distribution function (2PGDF). Recently, two-parameter gamma distribution and three-parameter beta distribution function (3PBDF) have sucessfully utilized in deriving synthetic unit hydrographs for Indian as well as Turkey catchments $[4,5$, 25]. However, SUH derivations require determination of the pdf parameters by the least square approach, nondimentional approach along with suitable optimization techniques or any other suitable error criteria [4].

In light of such advancements in SUH derivation, the objectives of this review paper are threefold: (i) to review the traditional synthetic unit hydrograph methods [8-10]; (ii) to review the SUH methods based on statistical distributions; and (iii) to present a comparison between SUHs derived from the popular methods [8-9], and those from statistical distributions (i.e. $2 \mathrm{PGDF}$ and $3 \mathrm{PBDF}$ ).

\section{TRADITIONAL SUH METHODS}

\section{Snyder's Method}

For the first time Snyder [8] established a set of empirical relationships, which relate the watershed characteristics, i.e. $\mathrm{A}=$ area of the watershed (Sq. miles); $\mathrm{L}=$ length of main stream (miles); and $\mathrm{L}_{\mathrm{c}}=$ the distance from the watershed 
outlet to a point on the main stream nearest to the center of the area of the watershed (miles) to the three basic parameters of the UH i.e. $t_{p}=$ lag to time to peak (hr); $Q_{p}=$ peak discharge rate $\left(\mathrm{ft}^{3} / \mathrm{s}\right)$; and $\mathrm{t}_{\mathrm{b}}=$ base time $(\mathrm{hr})$. This is used to describe the shape of the UH, expressible as

$$
\begin{aligned}
& \mathrm{t}_{\mathrm{p}}=\mathrm{C}_{\mathrm{t}}\left(\mathrm{LL}_{\mathrm{c}}\right)^{0.3} \\
& \mathrm{Q}_{\mathrm{p}}=640\left(\frac{\mathrm{AC} \mathrm{C}_{\mathrm{p}}}{\mathrm{t}_{\mathrm{p}}}\right) \\
& \mathrm{t}_{\mathrm{b}}=3+3\left(\frac{\mathrm{t}_{\mathrm{p}}}{24}\right)
\end{aligned}
$$

where $\mathrm{C}_{\mathrm{t}}$ and $\mathrm{C}_{\mathrm{p}}$ are nondimentional constants and in general varies from 1.8 to 2.2 and 0.56 to 0.69 , respectively. Eqs. (1) to (3) hold good rainfall-excess (RE) duration (or unit duration $=\mathrm{t}_{\mathrm{r}}$ ) as

$\mathrm{t}_{\mathrm{r}}=\frac{\mathrm{t}_{\mathrm{p}}}{5.5}$

If the duration of rainfall-excess, say $t_{r 1}$, is different from $t_{r}$ as defined above, a modified lag time $t_{p m}$ can be estimated from

$$
\mathrm{t}_{\mathrm{pm}}=\mathrm{t}_{\mathrm{p}}+\frac{\left(\mathrm{t}_{\mathrm{r} 1}-\mathrm{t}_{\mathrm{r}}\right)}{4}
$$

One can sketch many UHs through three known characteristic points of the $\mathrm{UH}$ (i.e. $\mathrm{t}_{\mathrm{p}}, \mathrm{Q}_{\mathrm{p}}$, and $\mathrm{t}_{\mathrm{b}}$ ), with its specific criteria, i.e. area under the SUH, to be unity. To overcome with this ambiguity associated with the Snyder's method, the U.S. Army Corps of Engineers [26] developed empirical equations between widths of $\mathrm{UH}$ at $50 \%$ and $75 \%$ of $\mathrm{Q}_{\mathrm{p}}$ i.e. $\mathrm{W}_{50}$ and $\mathrm{W}_{75}$ respectively as a function of $\mathrm{Q}_{\mathrm{p}}$ per unit area $\left(\mathrm{q}_{\mathrm{p}}\right)$, expressible as

$$
\begin{aligned}
& W_{50}=\frac{830}{q_{\mathrm{p}}^{1.1}} \\
& W_{50}=\frac{470}{q_{\mathrm{p}}^{1.1}}
\end{aligned}
$$

where $W_{50}$ and $W_{75}$ are in units of hour. Thus one can sketch a smooth curve through seven points $\left(t_{p}, t_{b}, Q_{p}, W_{50}\right.$, and $\mathrm{W}_{75}$ ) relatively in an easier way with less degree of ambiguity and to have the area under the SUH that equals to unity. However, this procedure is also tedius and involves great degree of subjectivity and error due to manually fitting of the points and simultaneous adjustments for the area under the SUH. For the present method (Eqs. 1-7), considering an exmple described by [4], observed flood data of MyntduLeska catchment (Maghalaya, India) are considered for comparing the flood hydrographs obtained using the observed one-hour hydrograph (unit rainfall in inch) with those computed using the above described approach. The catchment characteristics are described as: $\mathrm{A}=350 \mathrm{~km}^{2}$ (= $\left.135.135 \mathrm{mi}^{2}\right), \mathrm{L}=51.8 \mathrm{~km}, \mathrm{~L}_{\mathrm{CA}}=16.15 \mathrm{~km}, \mathrm{t}_{\mathrm{p}}=5 \mathrm{hr}, \mathrm{Q}_{\mathrm{p}}=$ $10603 \mathrm{ft}^{3} / \mathrm{s}$. For the Synder method: $\mathrm{C}_{\mathrm{p}}=0.65, \mathrm{t}_{\mathrm{p}}=6.2 \mathrm{hr}$, $\mathrm{q}_{\mathrm{p}}=0.13$ per $\mathrm{hr}, \mathrm{W}_{50}=6.42 \mathrm{hr}$, and $\mathrm{W}_{75}=3.64 \mathrm{hr}$, and $\mathrm{Q}_{\mathrm{p}}=$
$12073 \mathrm{ft}^{3} / \mathrm{s}$. Synder method slightly underestimates the peak discharge and the discharge in the rising phase, increases the time to peak, overestimates the recession part of the hydrograph, and consequently, increases the time base to conserve the flood hydrograph area. It is because the cathchment is considered to be ungauged i.e. without any observed flood data, which might be advantageous in such cases. In summary, the major inconsistensies associated with the method are:

(i) the manual fitting of the charateristic points needed great degree of subjectivity and trial and error, and may involve error;

(ii) the constants $\mathrm{C}_{t}$ and $\mathrm{C}_{\mathrm{p}}$ vary over wide range and from region to region, and may not be equally suitable for all the regions;

(iii) the time base (Eq. 3) of Snyder's method is always greater than three days, which is reasonable for fairly large watersheds only [1, 10, 12, 27].

\section{Taylor and Schwarz (TS) Model}

The TS model was proposed in [10] for SUH derivation. While deriving the SUH, the model specially considers the average slope of the main channel of the watershed and all the other watershed characteristics (i.e. A, L and $\mathrm{L}_{\mathrm{c}}$ ) similar to Snyder's method. The average slope of the main channel is determined as

$\mathrm{S}_{\mathrm{e}}=\left[\frac{\mathrm{N}}{\sum_{\mathrm{i}=1}^{\mathrm{N}}\left(1 / \mathrm{S}_{\mathrm{i}}\right)^{0.5}}\right]^{2}$

where $S_{e}=$ the average slope of the main channel; $S_{i}=$ the slope of the $i^{\text {th }}$ reach of the main channel; and $\mathrm{N}$ is the total number of reaches.

The empirical equations relating the $\mathrm{UH}$ characteristics to the watershed characteristics are expressed as

$\mathrm{t}_{\mathrm{p}}=\left(\frac{0.6}{\mathrm{~S}_{\mathrm{e}}^{0.5}}\right) \mathrm{e}^{\left(\mathrm{m}_{1} \mathrm{D}\right)}$

where $\mathrm{m}_{1}=0.212\left(\mathrm{LL}_{\mathrm{c}}\right)^{-0.36}$

$Q_{p}=\left(\frac{382}{\left(L_{c}\right)^{0.36}}\right) e^{\left(m_{2} \mathrm{D}\right)}$

where $\mathrm{m}_{2}=0.121 \mathrm{~S}_{\mathrm{e}}{ }^{0.142}-0.05-\mathrm{m}_{1}$

$\mathrm{t}_{\mathrm{b}}=5\left(\mathrm{t}_{\mathrm{p}}+\frac{\mathrm{t}_{\mathrm{r}}}{2}\right)$

In Eqs. (9-11), $t_{p}, L_{r}, L_{c}, t_{b}$ and $t_{r}$ are same as in the Snyder's method, and for D-hour rainfall for the UH duration. However, the peak discharge rate $\left(Q_{p}\right)$ is expressed in $\left(\mathrm{ft}^{2} / \mathrm{s} / \mathrm{mi}^{2}\right)$. Similar to the Snyder's method the TS model also estimates $\mathrm{W}_{50}$ and $\mathrm{W}_{75}$ using the equations proposed by U.S. Army Corps of Engineers [26] for smooth sketching of the SUH. 
It appears from Eq. (11) that the estimate of $t_{b}$ is somewhat consistent with the general notion that the $t_{b}$ can be taken as three to five times the time to peak for sketching the UH [27]. However, the basic inconsistencies associated with TS model remain as same as with the Snyder's method.

\section{Soil Conservation Service (SCS) Method}

The Soil Conservation Service method of U.S. Department of agriculture (USDA), uses a specific average dimensionless unit hydrograph $[9,11]$. It is derived from the analysis of large number of natural UHs for the watersheds of varying size and geographic locations, to synthesize the UH [7].

To enable defining time base, $t_{b}$, in terms of time to peak, $t_{p}$, and time to recession, $t_{r c}$, the SCS method represents the dimentionless $\mathrm{UH}$ as a triangular $\mathrm{UH}$, which further facilitates the computation of runoff volume $(\mathrm{V})$ and peak discharge $\mathrm{q}_{\mathrm{p}}$ as

$\mathrm{V}=\frac{\left(\mathrm{q}_{\mathrm{p}} \mathrm{t}_{\mathrm{b}}\right)}{2}=\frac{1}{2} \mathrm{q}_{\mathrm{p}}\left(\mathrm{t}_{\mathrm{p}}+\mathrm{t}_{\mathrm{rc}}\right) ;$ where $\mathrm{t}_{\mathrm{rc}}=1.67 \mathrm{t}_{\mathrm{p}}$

$q_{p}=0.749\left(\frac{\mathrm{V}}{t_{p}}\right)$

where $\mathrm{q}_{\mathrm{p}}$ is in $\mathrm{mm} / \mathrm{hr} / \mathrm{mm}$; V is in $\mathrm{mm}$; $\mathrm{t}_{\mathrm{p}}$ and $\mathrm{t}_{\mathrm{rc}}$ are in hrs.

To determine the complete shape of the SUH from the non-dimensional $\left(\mathrm{q} / \mathrm{q}_{\mathrm{p}} \mathrm{vs} \mathrm{t} / \mathrm{t}_{\mathrm{p}}\right)$ hydrograph, the time to peak is computed as

$\mathrm{t}_{\mathrm{p}}=\mathrm{t}_{\mathrm{L}}+\left(\frac{\mathrm{t}_{\mathrm{r}}}{2}\right)$

where $t_{L}=$ lag time from centroid of excess-rainfall to peak discharge $\left(\mathrm{q}_{\mathrm{p}}\right)$ in an hour; and $\mathrm{t}_{\mathrm{r}}=$ excess-rainfall duration for unit duration (hour).

The lag time $\left(t_{L}\right)$ can be estimated from the watershed characteristics using curve number $(\mathrm{CN})$ procedure as

$\mathrm{t}_{\mathrm{L}}=\frac{\mathrm{L}^{0.8}(2540-22.86 \mathrm{CN})^{0.7}}{14104 \mathrm{CN}^{0.7} \mathrm{Y}^{0.5}}$

Where $t_{L}=$ in hours; $L=$ hydraulic length of watershed $(m)$; $\mathrm{CN}=$ curve number $(50 \leq 95)$; and $\mathrm{Y}=$ average catchment slope in $(\mathrm{m} / \mathrm{m})$.

Alternatively Eq. (13) can be expressed as

$\mathrm{Q}_{\mathrm{p}}=2.08\left(\frac{\mathrm{A}}{\mathrm{t}_{\mathrm{p}}}\right)$

where $Q_{p}=$ peak discharge in $\mathrm{m}^{3} / \mathrm{s}$ for one $\mathrm{cm}$ of excessrainfall; $\mathrm{A}=$ area in $\mathrm{km}^{2}$.

Thus with known $\mathrm{q}_{\mathrm{p}}, \mathrm{t}_{\mathrm{p}}$, and specified dimentionless $\mathrm{UH}$, a SUH can be easily derived. Using the observed data of Myntdu-Leska catchment as in the previous example, the SCS method results are: $\mathrm{Q}_{\mathrm{p}}=6246.47 \mathrm{ft}^{3} / \mathrm{s}$ and $\mathrm{t}_{\mathrm{p}}=5.4 \mathrm{hr}$. The derived flood hydrograph is given in Fig. 1, and as observed from the results, the SCS method overestimates the peak discharge, underestimates the rising limb, and closely matches with the recession limb of the hydrograph. How-

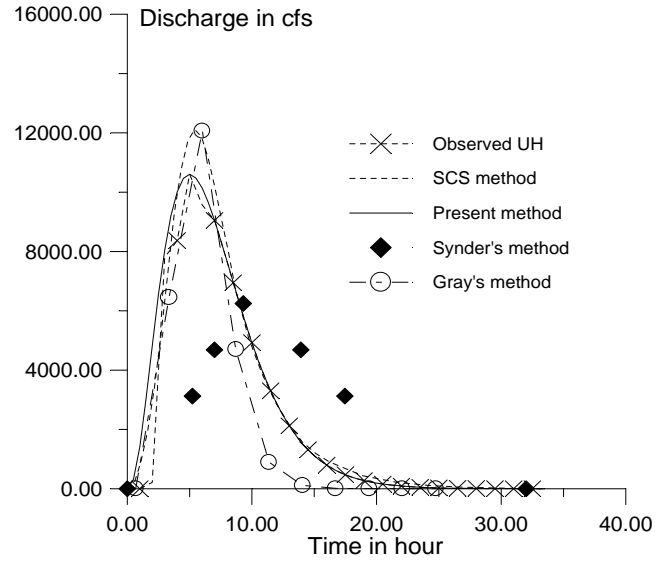

Fig. (1). Comparison of UHs developed by SCS, Snyder, and Gray method with the Bhunya et al. method for Myntdu-Leska catchment [25].

ever, the inconsistencies associated with the method can be enumerated as

(i) since the curve number method is applicable to watersheds of areas ranging from $8 \mathrm{~km}^{2}$ to $16 \mathrm{~km}^{2}$ [27], its application to large and mid size watersheds may lead to erroneous results.

(ii) since the SCS method fixes the ratio of time base to time to peak $\left(\mathrm{t}_{\mathrm{b}} / \mathrm{t}_{\mathrm{p}}\right)$ for triangular $\mathrm{UH}$ equal to 2.67 (or 8/3), ratios other than this may lead to the other shapes of the UH. In particular, larger ratio implies greater catchment storage. Therefore, since the SCS method fixes the ratio $\left(t_{b} / t_{p}\right)$, it should be limited to midsize watersheds in the lower end of the spectrum [27].

(iii) the SCS method is one of the popular methods for synthesizing the UH for only small watersheds of less than 500 square miles [28-30].

\section{Probability Distribution Function Based SUH Methods}

Use of probability distribution functions as SUH has a long history [18-22]. More recently, the potential of four popular pdfs, i.e. two-parameter Gamma, three-parameter Beta, two-parameter Weibull, and one-parameter Chi-square distribution were explored to derive SUH [31]. Following this, some of the relevant research work related to the use of distribution functions as SUH will be discussed here as follows:

\section{Gray's Method}

A dimensionless graph (empirical in nature) procedure based on two-parameter gamma distribution function and watershed characteristics were used to derive a SUH [1], and the geometry of dimensionless graph is expressed as

$$
\mathrm{Q}_{\mathrm{t} / \mathrm{P}_{\mathrm{R}}}=\frac{25.0\left(\gamma^{\prime}\right) \mathrm{q}}{\Gamma(\mathrm{q})}\left(\mathrm{e}^{-\gamma^{\prime} \mathrm{t} / \mathrm{P}_{\mathrm{R}}}\right)\left(\frac{\mathrm{t}}{\mathrm{P}_{\mathrm{R}}}\right)^{\mathrm{q}-1)}
$$

where $Q_{t / P_{R}}$ is the percent flow at any given $t / P_{R}$ value; $P_{R}=$ the time from beginning of surface runoff to the occurrence of peak discharge (minutes); $\gamma^{\prime}$ a dimensionless parameter $=$ $\gamma \mathrm{P}_{\mathrm{R}} ; \mathrm{q}=$ shape parameter $=1+\gamma^{\prime} ; \Gamma=$ gamma function. 
In the words of Gray [1] "Each graph was adjusted with the ordinate values expressed in percentage flow based on a time increment equal to $1 / 4$ th of the period of rise, $P_{R}$. The empirical graphs described in this manner were referred to as dimensionless graphs".

He defined the ratio $1 / \gamma=\mathrm{P}_{\mathrm{R}} / \gamma^{\prime}$ as the storage factor, a measure of the storage property of a watershed or the travel time required for water to pass through a given reach, and related it with the watershed characteristics in the form of a power equation as

$$
\frac{\mathrm{P}_{\mathrm{R}}}{\gamma^{\prime}}=\mathrm{a}\left(\frac{\mathrm{L}}{\sqrt{\mathrm{S}_{\mathrm{M}}}}\right)^{\mathrm{b}}
$$

where $\mathrm{a}$ and $\mathrm{b}$ are the coefficient and exponent of the power equation.

Eq. (18) was applied to 33 watersheds comprising of three regional groups: (i) Nebraska-Western Iowa; (ii) Central Iowa-Missouri-Illinois and Wisconsin; and (iii) Ohio, to estimate a and b. Finally, for each group Eq. (18) is expressed and $\mathrm{S}_{\mathrm{M}}$ is the slope of main stream in $\%$.

For Nebraska-Western Iowa:- $\frac{\mathrm{P}_{\mathrm{R}}}{\gamma^{\prime}}=7.40\left(\frac{\mathrm{L}}{\sqrt{\mathrm{S}_{\mathrm{M}}}}\right)^{0.498}$

For Central Iowa-Missouri-Illinois and Wisconsin: $\frac{\mathrm{P}_{\mathrm{R}}}{\gamma^{\prime}}=9.27\left(\frac{\mathrm{L}}{\sqrt{\mathrm{S}_{\mathrm{M}}}}\right)^{0.562}$

For Ohio: $-\frac{\mathrm{P}_{\mathrm{R}}}{\gamma^{\prime}}=11.40\left(\frac{\mathrm{L}}{\sqrt{\mathrm{S}_{\mathrm{M}}}}\right)^{0.531}$

where the ratio $P_{R} / \gamma^{\prime}$ is in minutes; $L=$ length of main stream in miles. Finally, he developed a regression relationship between the period of rise $P_{R}$ and dimensionless parameter $\gamma^{\prime}$ as

$$
\frac{\mathrm{P}_{\mathrm{R}}}{\gamma^{\prime}}=\frac{1}{\frac{2.676}{\mathrm{P}_{\mathrm{R}}}+0.0139}
$$

Thus Eqs. (17) to (22) are used to develop the dimensionless UH, and consequently the SUH. One of the best findings of the study is that the two-parameter gamma distribution can be used successfully to describe the synthetic unit hydrograph. The example discussed above is used for this case, $\mathrm{Q}_{\mathrm{p}}=12073 \mathrm{ft}^{3} / \mathrm{s}$ and $\mathrm{t}_{\mathrm{p}}=6.2 \mathrm{hr}$ computed for the Gray method, and the results of flood hydrograph are shown in Fig. 1. Gray method over-estimates the peak discharge, under-estimates discharges in both rising and receding phases of the hydrograph, and reduces the time base, as pointed in Synder method. However, the empirical relationships (Eqs. 19-22) are watershed size specific, and should be used with in the area limits for which these are developed $[1,12]$.

Croley [18] developed synthetic hydrograph by fitting two-parameter gamma distribution for different set of boundary conditions: $\left(t_{p}, q_{p}\right),\left(t_{p}, t_{I}\right)$ or $\left(q_{p}, t_{I}\right)$, where $t_{I}$ is the point of inflection [T], $\mathrm{q}_{\mathrm{p}}$ is the peak discharge per unit area per unit effective rainfall $\left[\mathrm{T}^{-1}\right]$, and $\mathrm{t}_{\mathrm{p}}$ is the time to peak [T]. These boundary conditions are used to estimate the parameters $\alpha$ and $\beta$ of the distribution. The general expression for the synthetic hydrograph is expressed as

$q(t)=\frac{V}{K \Gamma(n)}\left(\frac{t}{K}\right)^{n-1} e^{-\frac{t}{K}}$

where $\mathrm{V}$ is defined as

$\int_{0}^{\infty} \mathrm{q}(\mathrm{t}) \mathrm{dt}=\mathrm{V}$

It is interesting to note that if $\mathrm{V}$ corresponds to the volume of runoff produced by a unit depth of rainfall excess uniformly applied both spatially over the watershed area and temporarily over the storm duration, then $\mathrm{q}(\mathrm{t})$ (Eq. 23) is by definition, the "unit hydrograph" for that area and for that storm duration. It can be converted easily into hydrographs corresponding to other rainfall excess depths and storm durations by using linear superposition techniques already available $[32,33]$. The methodology provides a line of initiation to work with probability distribution functions for synthetic unit hydrograph derivation for ungauged catchments.

Haktanir and Sezen [21] explored the suitability of twoparameter gamma and three-parameter beta distributions as synthetic unit hydrographs for Anatolia catchments in Turkey. The analytical expressions for scale-adjusted gamma and beta distributions as SUH are expressed as

(i) Gamma Synthetic Unit Hydrograph

$\mathrm{Q}_{\mathrm{G}}(\mathrm{t})=(\mathrm{A} / 0.36) \frac{1}{\mathrm{~K} \Gamma(\mathrm{n})}(\mathrm{t} / \mathrm{K})^{\mathrm{n}-1} \mathrm{e}^{-\mathrm{t} / \mathrm{K}}$

where $\mathrm{Q}_{\mathrm{G}}(\mathrm{t})=$ the flow rate of the gamma $\mathrm{SUH}$ at time $\mathrm{t}$ in $\mathrm{m}^{3} / \mathrm{s} / \mathrm{cm} ; \mathrm{A}=$ watershed area in $\mathrm{km}^{2} ; \mathrm{t}=$ time in hours; $\mathrm{n}$ is the number of linear reservoirs, and $\mathrm{K}$ is the storage coefficient of the reservoirs in units of hours.

(ii) Beta Synthetic Unit Hydrograph

$\mathrm{Q}_{\mathrm{B}}(\mathrm{t})=(\mathrm{A} / 0.36)\left[\mathrm{t}^{\mathrm{r}-1}(\mathrm{~b}-\mathrm{t})^{\mathrm{p}-\mathrm{r}-1}\right] /\left[\mathrm{Bb}^{\mathrm{p}-1}\right]$

where $\mathrm{B}$ is given as

$\mathrm{B}=[\Gamma(\mathrm{r}) \Gamma(\mathrm{p}-\mathrm{r})] / \Gamma(\mathrm{p})$

where $\mathrm{Q}_{\mathrm{B}}(\mathrm{t})$ is the flow rate of beta $\mathrm{SUH}$ at time $\mathrm{t}$ in $\mathrm{m}^{3} / \mathrm{s} / \mathrm{cm} ; \mathrm{r}$ and $\mathrm{p}$ are the shape parameters; $\mathrm{b}$ is the scale parameter in hours. The parameters of both distributions were estimated by using classical Newton iterative algorithm. They found that both the distributions fit reasonably well to observed unit hydrographs. These are discussed briefly with field data in [34].

Bhunya et al. [4] introduced a simplified version of twoparameter gamma distribution to derive a synthetic unit hydrograph more conveniently and accurately than the popular Snyder, SCS, and Gray methods. The analytical form of the model is expressed as 
$q(t)=\frac{1}{K \Gamma(n)}\left(\frac{t}{K}\right)^{n-1} e^{\left(-\frac{t}{K}\right)}$

where $q(t)$ is the depth of runoff per unit time per unit effective rainfall. The parameters $n$ and $K$ are often termed as the shape and scale parameters, respectively of the model. It is noteworthy that parameter $\mathrm{n}$ is dimensionless, and $\mathrm{K}$ has the unit of time. The area under the curve defined by Eq. (28) is unity. Thus the rainfall-excess and direct surface runoff depths are equal to unity.

The authors defined a non-dimensional term $\beta=\mathrm{q}_{\mathrm{p}} \mathrm{t}_{\mathrm{p}}$, where $\mathrm{q}_{\mathrm{p}}$ and $\mathrm{t}_{\mathrm{p}}$ are peak flow rate and time to peak flow rate, respectively, and are easily derived from Eq. (28). The expression for $\beta$ was derived as

$$
\beta=\frac{(\mathrm{n}-1)^{(\mathrm{n}-1)} \mathrm{e}^{-(\mathrm{n}-1)}}{\mathrm{A}(\mathrm{n}-1)}
$$

Since the exact solution of $n$ in terms of $\beta$ from Eq. (29) is not possible, they developed simpler relationships between $\mathrm{n}$ and $\beta$ to obtain the simplified versions of gamma distribution. The developed relationships are given as

$$
\mathrm{n}=5.53 \beta^{1.57}+1.04 \quad \text { for } 0.01<\beta<0.35 ; \mathrm{COD}=1
$$

And

$$
\mathrm{n}=6.29 \beta^{1.998}+1.157 \text { for } \beta \geq 0.35 ; \mathrm{COD}=1
$$
(28) as

Finally, the scale parameter $\mathrm{K}$ can be derived from Eq.

$\mathrm{K}=\mathrm{t}_{\mathrm{p}} /(\mathrm{n}-1)$

Now for known values of $\mathrm{n}$ from a given $\beta$, one can easily get the value of $\mathrm{K}$ from Eq. (31). Thus it eliminates the cumbersome trial and error solutions for $\mathrm{n}$ and K. One thousand sets of $(n, \beta)$ values with $n$ ranging from 1 to 40.0 and $\beta$ ranging from 0.01 to 2.5 were considered for developing the relationships. The major findings of the study are: (i) $\mathrm{n}$ can be expressed mathematically in terms of $\beta$ in a simple but accurate form; (ii) the parameter $\mathrm{n}$ and dimensionless term $\beta$ are dependent not only on the physical characteristics of the watershed, but also on its storage characteristics; and (iii). The present approach worked better than the Snyder, SCS, and Gray methods, as shown in Fig. (1).

Jena and Tiwari [35] modeled the parameters of SUH using the geomorphologic parameters (channel as well as basin parameters) of two watersheds in India. Basin parameters were obtained from the Survey of India maps using geographical information system (GIS) techniques and drainage network updated from Indian remote sensing satellite digital images. This study was undertaken in two medium sized agricultural watersheds. A correlation matrix between $\mathrm{UH}$ parameters and geomorphologic parameters was generated and geomorphologic parameters having higher degree of correlation with UH parameters were selected. Regression equations were developed between individual UH parameters and one of the geomorphologic parameters obtained in previous step. Then non-linear regression models were developed between UH parameters and the above-selected geomorphologic parameters. All developed models for Tarafeni watershed and its sub watersheds were tested using different statistical tests for different rainfall events. These models were suggested to be suitable for small and medium agricultural sub tropical sub humid basins having similar geohydrological conditions.

Bhunya et al. [31] explored the potential of four popular pdfs, i.e., two-parameter Gamma, three-parameter Beta [25], two-parameter Weibull, and one-parameter Chi-square distribution to derive SUH. For the reasons of non-availability of an explicit parameter estimation procedure, pdf parameters are determined using the least square approach or any other optimization procedures with suitable error criteria. In this referred work, the authors developed simple analytical and numerical relationships to compute the distribution parameters, and checked their validity using simulation and field data. Fig. (2) shows the SUHs developed by different pdfs. It can be observed from Fig. (2) that the pdfs performs more satisfactorily than the traditional method of SUHs. Though all the considered pdfs describe the UH shape well, the major disadvantage with them, except Beta-distribution, is their inability to yield a fixed $t_{B}$-value. The Gamma, Weibull, and Chi-square distributions yield time to base approaching infinity when q approaches zero. Since Beta and Weibull distributions skew on both sides (positive and negative) similar to an UH encountered in practice, they are more flexible in description of SUH shape, as also observed in applications of these methods to field data by giving least fitting errors. Compared to work referred in [4] discussed earlier i.e. the results shown in Fig. (1), the works referred by [31] have an advantage that an idea about the influence of time to base and time to peak on the statistical properties of the UH is focussed here, and a sensitivity analysis of pdf parameters on the peak flow estimates, and other UH points like scale, and shape are discussed in detail.

Some of the important conclusions drawn from the study are:

(i) given two points on the UH, e.g., time to peak and peak flow, these pdfs can be used to describe the shape of the unit hydrograph, and they perform better than the existing synthetic methods, i.e. methods suggested are discussed in $[1,8,9,11]$.

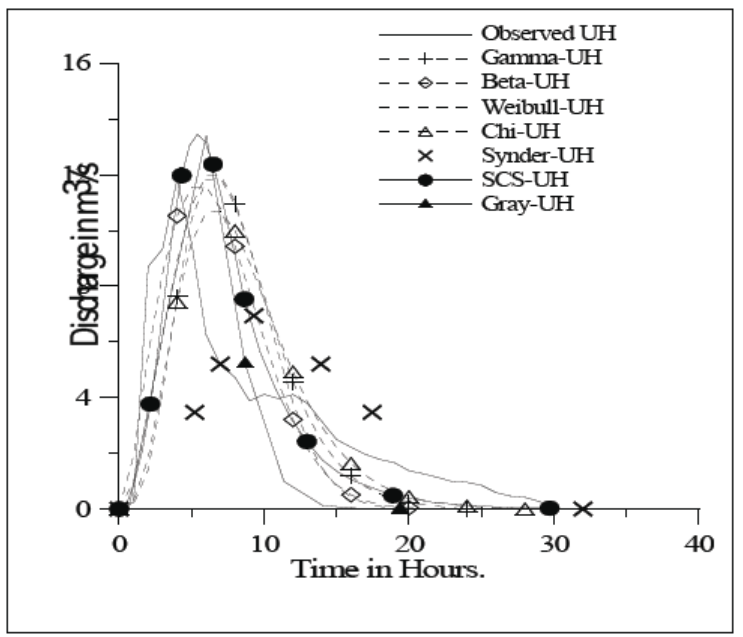

Fig. (2). Comparison of UHs developed by Gamma, Beta, Weibull, Chi Square, SCS, Snyder, and Gray method for Myntdu-Leska catchment [31]. 
(ii) the proposed analytical solutions for parameter estimations are simple to use, and gives accurate results of the actual pdf parameters.

(iii) among the four pdfs analyzed in the study, the Beta and Weibull distributions are more flexible in description of SUH shape as they skew on both sides similar to a UH, and on the basis of their application to field data.

(iv) as the Beta distribution approximates a Gamma distribution in a limiting case and Gamma and Chi-square distribution behaves similarly, the Beta distribution should be a preferred method for deriving SUH.

Bhunya et al. [36] explored the potential of two pdfs, two-parameter Weibull distribution (2PWD) and twoparameter Gamma distribution (2PGD) to derive SUH. Some of the important conclusions drawn from the study are as under.

The two-parameter Weibull distribution (2PWD) similar to an instantaneous unit hydrograph (IUH) is parameterized in terms of the Horton order ratios of a catchment on the basis of a geomorphologic model of catchment response. For this the shape and scale parameters of the Weibull distribution are expressed analytically in terms of Horton's number of a catchment. The proposed analytical expression gives accurate results when tested using simulated and field data. The two parameters of the IUH derived using Nash's model which is a two-parameter Gamma distribution (2PGD) are also expressed analytically in terms of Horton's order ratios of a catchment. The performance of the proposed methods is tested describing a synthetic unit hydrograph (SUH) for limited data conditions. A comparison is made with the observed hydrographs for two real catchments, and with the existing geomorphological based 2PGD for developing SUH is given by [37]. The sensitivity of the 2PWD to the nondimensional parameter $\beta$ of the UH (a product of peak discharge and time to peak) is examined using simulated data for different scenarios. The results show $\beta$ to be more sensitive to the scale parameter $a$ in the case of 2PWD than the shape parameter $b$, and the rate of change in $\beta$ is positive for $a<5$. The rate of change in $\beta$ is negative to any change in $b$ for $a>6.2$, and depends upon time to peak with an inverse relationship. Further examination to find any similarity between the behavior of 2PWD and 2PGD showed that $a$ in 2PWD corresponds to the scale parameter $k$ in the 2PGD, and $b$ behaves similar to the shape parameter $n$ in the 2PGD. Finally, practical applicability of the proposed approach to ungauged catchments is tested using field data.

Fig. 3 shows the SUHs developed by different methods discussed so far, and the observed data from Bridge catchment (Madhya Pradesh, India) are considered here for partial data conditions. And, it can be observed that the unit hydrograph derived using the proposed analytical and numerical approach performs marginally better than the approach given by Rosso [37].

This means that the unit hydrograph derived by using the 3PGD method with the numerical approach performs marginally better than the other two methods. For the Bridge catchment, the standard error using Rosso, proposed analytical, and numerical approaches are found to be $0.68,0.68$, and 0.64 respectively. This means that the unit hydrograph derived by using the proposed analytical and numerical approaches performs marginally better than the method by Rosso [37].

The following conclusions are drawn from the study:

(i) Expressing parameters of the 2PGD in terms of Horton order ratios by the numerical method shows better accuracy as compared to the method given by Rosso [37].

(ii) For describing shape of the SUH with limited data conditions, the proposed 2PWD approach is marginally better than the existing 2PGD.

(iii) The nondimensional UH parameter $\beta$ for $2 \mathrm{PWD}$ is more sensitive to the scale parameter $a$ than the shape parameter $b$, and the rate of change in $\beta$ is positive for $a<5$. The rate of change in $\beta$ is negative to any change in $b$ for $a>6.2$, and depends on the time to peak with an inverse relationship.

(iv) An analytical diagnosis of both pdfs indicates a similar behavior between 2PWD and 2PGD and statistical properties of the UH.

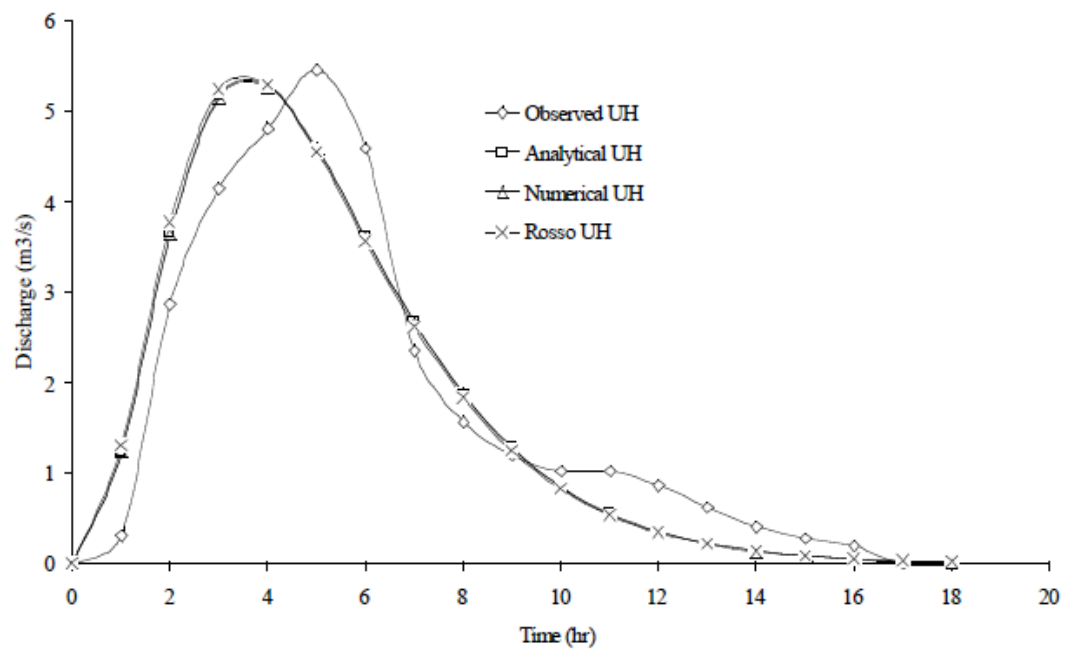

Fig. (3). 2PGD-SUH derived for the Bridge catchment for partial data conditions [6]. 
Fig. (3) shows the SUHs developed by different methods, and it can be observed that the unit hydrograph derived using the proposed analytical and numerical approach performs marginally better than approach given by Rosso [37].

Furthermore, the history and procedures for several unit hydrograph methods are presented by [38-41], and reported that the synthetic unit hydrograph of Snyder in 1938 was based on the study of 20 watersheds located in the Appalachian Highlands and varying in size from 10 to 10,000 square miles ( 25 to $25000 \mathrm{~km}^{2}$ ). Further, it was reported that dimensionless unit hydrograph was developed by the Soil Conservation Service and obtained from the UH's for a great number of watersheds of different sizes and for many different locations [41]. He further stated that the SCS dimensionless hydrograph is a synthetic UH in which the discharge is expressed as a ratio of discharge, $\mathrm{Q}$, to peak discharge, $\mathrm{Q}_{\mathrm{p}}$ and the time by the ratio of time, $t$, to time to peak of the $\mathrm{UH}, \mathrm{t}_{\mathrm{p}}$. [39] also reported that in 1938, McCarthy proposed a method of hydrograph synthesis but in that same year, Snyder proposed a better known method by analyzing a larger number of basins in the Appalachian mountain region of the United States. Four methods of unit hydrographs generation to develop unit hydrograph were applied for an ungaged watershed [42], and the outcome of the study revealed that both Snyder and SCS methods were not significantly different from each other.

Salami et al. [43] presented the establishment of appropriate method of synthetic unit hydrograph to generate ordinates of design storm hydrographs for eight river catchment in the South West Nigeria. The authors concluded that the values of peak flows obtained by Gray and SCS methods for five watershed were relatively close, while values of peak flows obtained by Gray and Snyder methods for two watershed were relatively close and the values of peak flows obtained by Snyder and SCS methods for only one watershed were relatively close. The authors inferred that SCS method can be used to estimate ordinate required for the development of peak storm hydrograph of different return periods for the river watersheds considered.

Adebayo et al. [44] presented the establishment of appropriate method of synthetic unit hydrograph to generate ordinates for the development of design storm hydrographs for the catchment of eight selected rivers located in the South West Nigeria. Unit hydrographs were developed based on Snyder, Soil Conservation Service (SCS) and Gray methods; while the SCS curve Number method was used to estimate the cumulative rainfall values for storm depth of different return periods. The authors inferred that SCS method can be used to estimate ordinate required for the development of peak storm hydrograph of different return periods for the river watersheds considered.

\section{CONCLUSIONS}

The study on SUHs review reported herein mainly concentrates on two aspects: (i) the traditional methods of SUH derivation, e.g., Snyder's method, SCS method, and TS method; and (ii) the pdfs based SUH methods along with the recent adavacements. It can be inferred from the study that, albeit the methods of Snyder and SCS are used widely in practical engineering problems, but the manual fitting of the charateristic points needed great degree of subjectivity and trial and error, and may involve error. Also each time it is not possible to get the area under the curve to be unity, which is the prerequisite for UH derivation. This questions the wider applicability and acceptibility for practical field applications. On the other hand, the pdfs based SUH methods gives the complete shape of unit hydrograph, and the area under the curve is guaranteed to be unity. Well tested and applied relationships have been developed to estimate the parameters of pdfs. This strong mathematical perception and conceptual basis of pdfs successfully fill the technological niche for SUHs derivation.

\section{REFERENCES}

[1] Gray DM. Synthetic hydrographs for small drainage areas. Proc ASCE 1961; 87 HY4: 33-54.

[2] Sherman LK. Streamflow from rainfall by the unit hydrograph method. Engrg News Rec 1932; 108: 501-5.

[3] Todini E. Rainfall-runoff modeling-past, present and future. J Hydrol Elsevier 1988; 100: 341-52.

[4] Arora KR. Irrigation, water power and water resources engineering. standard publishers, Delhi 2004; 1705-B: pp. 79-106.

[5] Bernard M. An approach to determinate stream flow. Trans ASCE 1935; 100: 347-95.

[6] Bhunya PK, Mishra SK, Berndtsson R. Simplified two parameter gamma distribution for derivation of synthetic unit hydrograph. J Hydrol Eng ASCE 2003; 8(4): 226-30.

[7] Singh VP. Hydrologic systems: Rainfall-runoff modeling. Vol-1. NJ Prentice Hall. Englewood: 1988.

[8] Snyder FF. Synthetic unit hydrographs. Trans Am Geophysics Union 1938; 19: 447-54.

[9] SCS. Soil Conservation Service. Design of hydrograph. US Department of Agriculture. Washington, DC 2002.

[10] Taylor AB, HE Schwarz. Unit hydrograph lag and peak flow related to basin characteristics. Trans Am Geophys Union 1952; 33 235-46.

[11] SCS. Soil Conservation Service. Use of storm and watershed characteristics in synthetic hydrograph analysis and application: V Mockus. U.S. Dept. of Agriculture, Washington, DC 1957.

[12] Gray DM. Interrelationship of watershed characteristics. J Geophys Res 1961; 66: 1215-23.

[13] Espey WH. Jr, Winslow DE. Urban flood frequency characteristics. Proc ASCE 100 HY2 1974; 100: 179-293.

[14] Miller AC, Kerr SN, Spaeder DJ. Calibration of Snyder coefficients for Pennsylvania. Water Resour Bull 1983; 19(4): 625-30.

[15] Hudlow MD, Clark DM. Hydrological synthesis by digital computers. J Hydrol Div ASCE 1969; 95(3): 839-60.

[16] Chow VT, Maidment DR, Mays LW. Applied hydrology. McGraw - Hill Publishing Company, New York 1988.

[17] Sokolov AA, Rantz SE, Roche M. Methods of developing design flood hydrographs: Flood computation methods compiled from world experience. UNESCO, Paris 1976.

[18] Croley TE. Gamma synthetic hydrographs, J Amsterdam Hydrol 47, Amsterdam 1980; 41-52.

[19] Aron G, White EL. Fitting a gamma distribution over a synthetic unit hydrograph. Water Resour Bull 1982; 18(1): 95-8.

[20] Aron G, White EL. Fitting a gamma distribution over a synthetic unit hydrograph. J Am Water Resour Assoc 2007; 18(1): 95-8.

[21] Haktanir T, Nurullah S. Suitability of two-parameter gamma distribution and three-parameter beta distribution as synthetic hydrographs in Anatolia. Hydrlol Sc J 1990; 35(2): 167-84.

[22] Yue S, Taha BMJ, Bernard Bobee, Legendre P, Pierre B. Approach for describing statistical properties of flood hydrograph. J Hydrol Eng ASCE 2002; 7(2): 147-53.

[23] Nash JE. Synthetic determination of unit hydrograph parameters. J Geophys Res 1959; 64(1): 111-5.

[24] Dooge JCI. A general theory of the unit hydrograph. J Geophys Res 1959; 64(2): 241-56.

[25] Bhunya PK, Mishra SK, Ojha CSP, Berndtsson R. Parameter estimation of beta distribution for unit hydrograph derivation. J Hydrol Eng ASCE 2004; 9(4): 325-32. 
[26] U. S. Army Corps of Engineers (USACE). Flood hydraulics package. User's Manual for HEC-1. CPD-1A; Version 4.0, USACE, Washington DC, 1990.

[27] Ponce VM. Engineering hydrology: Principles and practice. Prentice-Hall, Englewood Cliffs, NJ 1989; pp. 175-82.

[28] Wu IP. Flood hydrology of small watersheds: evaluation of time parameters and determination of peak discharge. Trans ASAE 1969; 12: 655-60.

[29] Wang RY, Wu IP. Characteristics of short duration unit hydrograph. Trans ASAE 1972; 15: 452-6.

[30] McCuen RH, Bondelid TR. Estimating unit hydrograph peak rate factors. J Irrigation Drainage Eng ASCE 1983; 110(7): 887-904.

[31] Bhunya PK, Berndtsson R, Ojha CSP, Mishra SK. Suitability of Gamma, Chi-square, Weibull and Beta distributions as synthetic unit hydrographs. J Hydrol Elsevier 2007; 334: 28-38.

[32] Linsley RK, Kohler MA, Paulhus JLH. Hydrology for engineers. McCraw-Hill, New York, 1975.

[33] Croley TE. Hydrologic and hydraulic computations on small programmable calculators. Iowa Institute of Hydraulic Research, University of Iowa, 1977; p. 837.

[34] Bhunya PK, Ghosh NC, Mishra SK, Ojha CSP, Berndtsson R. Hybrid model for derivation of synthetic unit hydrograph. J Hydrol Eng ASCE 2005; 10(6): 458-67.

[35] Jena SK, Tiwari KN. Modeling synthetic unit hydrograph parameters with geomorphologic parameters of watersheds. J Hydrol Elsevier 2006; 319(14): 1-14.

[36] Bhunya PK, Berndtsson R, Singh PK, Hubert P. Comparison between Weibull and gamma distributions to derive synthetic unit hydrograph using Horton ratios. Water Resour Res 2008; 44: WR006031.

[37] Rosso R. Nash model relation to Horton order ratios. Water Resour Res 1984; 20(7): 914-20.

[38] Viessman W, Knapp JW, Lewis GL. Introduction to hydrology. Harper and Row Publishers. New York, 1989; pp. 149-355.

[39] Wanielista MP. Hydrology and water quantity control. John Willey and Sons, Inc. 1990.

[40] Langbein WB, Iseri KT., Topographic characteristics of drainage basins. Water supply paper 968-C, U.S. Geological survey. 1947; pp. 125-155.

[41] Ramirez JA. Prediction and modeling of flood hydrology and hydraulics. Chapter 11 of Inland Flood Hazards: Human, Riparian and Aquatic Communities. Edited by Ellen Wohl. Cambridge University Press 2002.

[42] Ogunlela AO, Kasali MY. Evaluation of four methods of storm hydrograph development for an ungauged watershed. Nigerian $\mathrm{J}$ Technol develop 2002; (2): 25-34.

[43] Salami AW, Bilewu SO, Ayanshola AM, Oritola SF. Evaluation of synthetic unit hydrograph methods for the development of design storm hydrographs for Rivers in South-West, Nigeria. J Am Sci 2009; 5 (4): 23-32.

[44] Adebayo WS, Solomon OB, Ayanshola AM, Oritola SF. Evaluation of synthetic unit hydrograph methods for the development of design storm hydrographs for Rivers in South-West, Nigeria. J Am Sci 2009; 5(4): 23-32

Received: October 12, 2010

Revised: November 25, 2010

Accepted: November 25, 2010

(C) Bhunya et al.; Licensee Bentham Open.

This is an open access article licensed under the terms of the Creative Commons Attribution Non-Commercial License (http://creativecommons.org/licenses/by-nc/3.0/) which permits unrestricted, non-commercial use, distribution and reproduction in any medium, provided the work is properly cited. 